\title{
Endogenous electric field as a bridge for antibacterial ion transport from implant to bacteria
}

\author{
Jinxia Zhai ${ }^{1,2 \dagger}$, Yahong Zhou ${ }^{3 \dagger}$, Zhengao Wang ${ }^{1,2}$, Lei Fan ${ }^{1,2}$, Cairong Xiao ${ }^{1,2}$, Xiaolan Wang ${ }^{1,2}$, \\ Yangfan $\mathrm{Li}^{1,2}$, Zhengnan Zhou ${ }^{1,2}$, Yian Luo ${ }^{4}$, Changhao Li ${ }^{1,2}$, Suijian Qi ${ }^{5}$, Guoxin Tan ${ }^{4}$, Lei Zhou ${ }^{1,2^{*}}$, \\ Peng $\mathrm{Yu}^{1,2^{*}}$ and Chengyun Ning ${ }^{1,2^{*}}$
}

\begin{abstract}
Tissue implant-related infections are among the most serious complications after surgical implantation, including orthopedics and dentistry. Implants with antibacterial ion release systems are efficient and economical antibiotic substitutes to fight against bacterial infections. However, the excessive amount of released antibacterial ions may cause biological toxicity while killing bacteria. This raises a fundamental issue on how to properly control the amounts of ions and their efficacy. Here, we develop low-dose antibacterial ions-incorporated ferroelectric implants (copper-doped potassium sodium niobate, $\mathrm{K}_{0.5} \mathrm{Na}_{0.5} \mathrm{NbO}_{3}-\mathrm{Cu}, \mathrm{KNNCu}$ ) whose surface potential can be tuned via external polarization. The released $\mathrm{Cu}^{2+}$ ions can be targeted to bacteria via endogenous electric field (EEF) between KNNCu implants and negatively charged bacteria. Intriguingly, the antibacterial efficacy of the implants is determined by the amount of $\mathrm{Cu}^{2+}$ ions that reaches bacteria, instead of the total amount of released $\mathrm{Cu}^{2+}$ ions. The amount of $\mathrm{Cu}^{2+}$ ions reaching bacteria from the high-surface-potential implant is $\mathbf{2 . 4}$ times that from the lowsurface-potential implant within $12 \mathrm{~h}$, resulting in the increased antibacterial ratio from about $65 \%$ to $100 \%$, while remaining low cell toxicity. This work provides insights into the specific role of the EEF in guiding mass transport between charged materials and living organisms, and a new perspective for the design of high-performance antibacterial biomaterials.
\end{abstract}

Keywords: bacterial infection, endogenous electric field, ion transport, ferroelectric implant

\section{INTRODUCTION}

Bacterial infection is a major threat to human health, especially in surgeries involving large exposure of tissue to exogenous implants, such as orthopedics, and in dental and cardiovascular surgeries [1-4]. In order to protect tissue defects from bacterial infection, antibacterial ions and antibiotics are frequently incorporated into implants to enhance their antibacterial performance [5-10]. However, current studies ignore that most of the released antibacterial ions will randomly diffuse to the bacterial surrounding environment instead of penetrating the bacteria to exert an effect [11-14]. In other words, only a small portion of the released antibacterial ions can ultimately target the bacterial cell membrane. The low transport ratio of antibacterial ions hinders the work efficiency of these antibacterial ions-loaded implant materials. A reasonable hypothesis is that manipulation of antibacterial ions to target the bacterial cell membrane would enhance their antibacterial performance. Thus, developing new strategies to promote the transport of antibacterial ions to target bacteria is in urgent need for enhancing the antibacterial performance of implants.

Actually, as bacterial cell membrane is composed of lipids with negative charges $[15,16]$, once they approach charged implant surface, an endogenous electric field (EEF) naturally forms between the implant and the bacterial cell membrane, which can guide electric transport of mass to bacterial surface. However, most previous

\footnotetext{
${ }^{1}$ School of Materials Science and Engineering, South China University of Technology, Guangzhou 510640, China

${ }^{2}$ School of Biomedical Sciences and Engineering; National Engineering Research Center for Tissue Restoration and Reconstruction; Key Laboratory of Biomedical Engineering of Guangdong Province; Key Laboratory of Biomedical Materials and Engineering of the Ministry of Education; Innovation Center for Tissue Restoration and Reconstruction. South China University of Technology, Guangzhou 510006, China

${ }^{3}$ CAS Key Laboratory of Bio-inspired Materials and Interfacial Science, Technical Institute of Physics and Chemistry, Chinese Academy of Sciences, Beijing 100190, China

${ }^{4}$ School of Chemical Engineering and Light Industry, Guangdong University of Technology, Guangzhou 510006, China

${ }^{5}$ School of Food Science and Engineering, South China University of Technology, Guangzhou 510640, China

$\dagger$ These authors contributed equally to this work.

* Corresponding authors (emails: zhoul@scut.edu.cn (Zhou L); imyup@scut.edu.cn (Yu P); imcyning@scut.edu.cn (Ning C))
} 
studies did not take the EEF between implant and bacterial cell membrane into consideration, which leads to low antibacterial ion transport ratio [17-19]. It is reasonable to hypothesize that the EEF gererated via manipulating the surface potential of the implant material will enhance the electric transport of antibacterial ions to target the bacterial membrane to increase the bacteriakilling efficacy.

In this research, we propose to achieve directional and quantitative transport of antibacterial ions to target bacteria via modulation of EEF to enhance pathogenic bacterial killing. In order to construct an implant model with regulatable EEF-mediated antibacterial ions, we design a ferroelectric copper-doped implant, potassium sodium niobate $\left(\mathrm{K}_{0.5} \mathrm{Na}_{0.5} \mathrm{NbO}_{3}-\mathrm{Cu}, \mathrm{KNNCu}\right)$, whose surface potential can be finely tuned via external electric field polarization to reverse its dipole direction [20]. Once in an infectious bacterial environment, an EEF will establish between the positively charged implant and negatively charged bacterial cell membrane to guide directional and quantitative transport of antibacterial ions to target the bacterial cell membrane (Scheme 1). Both the polarized implant and charged microorganisms constitute the EEFcontrolled $\mathrm{Cu}^{2+}$ ion transport system to target bacteria for enhancing antibacterial property.

\section{EXPERIMENTAL SECTION}

\section{Fabrication of $\mathrm{KNNCu}$}

$\mathrm{KNN}$ doped with $\mathrm{CuO}$ was prepared by using a solid-state reaction method. KNN was first synthesized from the potassium carbonate $\left(\mathrm{K}_{2} \mathrm{CO}_{3}, 99.0 \%\right)$, sodium carbonate $\left(\mathrm{Na}_{2} \mathrm{CO}_{3}, 99.8 \%\right)$ and niobium oxide $\left(\mathrm{Nb}_{2} \mathrm{O}_{5}, 99.9 \%\right)$ powders, which were purchased from Aladdin Industrial Inc. Firstly, the mixture of above raw materials was dried after $8 \mathrm{~h}$ ball grinding and then calcined at $750^{\circ} \mathrm{C}$ for $2 \mathrm{~h}$ to obtain $\mathrm{KNN}$. Then, $0.5 \mathrm{wt} \%$ copper oxide powder ( $\mathrm{CuO}, 99 \%$, Aladdin Industrial Inc.) was doped into $\mathrm{KNN}$ to prepare the $\mathrm{KNNCu}$ powder. $\mathrm{KNNCu}$ samples were prepared by initially compressing (40 MPa), cold isostatic pressing (190 MPa for $5 \mathrm{~min})$ and sintering $\left(1050^{\circ} \mathrm{C}\right.$ for $2 \mathrm{~h}$ ). These samples were polarized under the external electric fields of 3 and $5 \mathrm{kV}$, respectively, for $10 \mathrm{~min}$. The $\mathrm{KNNCu}$ samples are named according to their different potentials, $\mathrm{H}-\mathrm{KNNCu}(\mathrm{KNNCu}$ with high surface potential), $\mathrm{M}-\mathrm{KNNCu}(\mathrm{KNNCu}$ with mediate surface potential), and $\mathrm{L}-\mathrm{KNNCu}$ (unpolarized $\mathrm{KNNCu}$ with low surface potential). The thickness of the $\mathrm{KNNCu}$ piezoelectric ceramics used in bacterial studies and cell studies was about $2 \mathrm{~mm}$ and the surface area was about

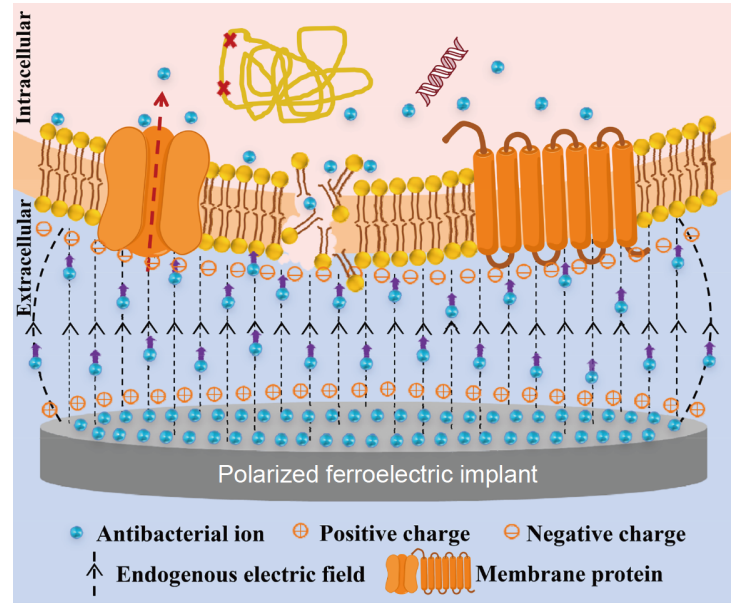

Scheme 1 Schematic illustration of the electric transport of antibacterial ions driven by an EEF established between the polarized ferroelectric implant and the negatively charged bacterial cell membrane as a bridge. Under the action of EEF, the amount of antibacterial ions transport to target bacteria increases, which can enhance the antibacterial property.

$63.62 \mathrm{~mm}^{2}$ (about $9 \mathrm{~mm}$ diameter).

\section{Characterization of $\mathrm{KNNCu}$}

The morphology and elemental distribution of $\mathrm{KNNCu}$ were characterized by using the field emission scanning electron microscopy (FE-SEM) (Zeiss EVO18, Carl Zeiss Company, Germany) equipped with energy dispersive spectroscopy (EDS, OxFord instruments X-Max Extreme). X-ray diffraction (XRD, Bruker D8 advance, Germany) was used for the crystalline phase analysis. The chemical constitution of $\mathrm{KNNCu}$ was checked via X-ray photoelectron spectroscopy (XPS, Axis Ultra DLD Kratos Company). The surface potentials of the $\mathrm{KNNCu}$ samples were characterized by scanning Kelvin probe force microscopy (SKPM, MFP-3D-S, Asylum Research, USA) by averaging the data from randomly selected areas $(1 \mu \mathrm{m} \times$ $1 \mu \mathrm{m})$ on the substrates. The polarization-electric $(P-E)$ hysteresis loop of $\mathrm{KNNCu}$ was measured by a TF analyzer (Model 2000E, aixACCT Systems, Germany).

\section{Antibacterial property}

The antibacterial activities of the $\mathrm{KNNCu}$ samples were examined by using two clinical bacterial species, Escherichia coli (E. coli) and Staphylococcus aureus (S. aureus), separated from clinical patients. The clinical bacteria were isolated according to the National Guide to Clinical Laboratory Procedures and characterized by culturing in the specifically appropriate media followed by the matrixassisted laser desorption/ionization-time of flight (MALDI-TOF) VITRK mass spectrometry microbial identifi- 
cation system (bioMerieux, France). Bacteria were grown in nutrient bouillon at $37^{\circ} \mathrm{C}$ at $150 \mathrm{r} \mathrm{min}^{-1}$ for $10-12 \mathrm{~h}$. The nutrient bouillon and nutrient agar medium were supplied by Oxoid Ltd. E. coli and S. aureus were suspended in phosphate-buffered saline (PBS) to obtain a concentration of $10^{6}$ colony-forming unit $(\mathrm{CFU}) / \mathrm{mL}$ for the antibacterial assay, and an extra $1 \%$ of the nutrient broth of bacterial suspension was added. The samples $(n=4)$ and bacterial suspension were co-incubated in a biochemical incubator at $37^{\circ} \mathrm{C}$ for $12 \mathrm{~h}$. Then, after coculture, the bacterial suspension was diluted to a proper concentration, and $50 \mu \mathrm{L}$ of the diluted bacterial suspension was uniformly spread on the nutrient agar medium plates. The number of CFUs was counted after incubation at $37^{\circ} \mathrm{C}$ for $16 \mathrm{~h}$. To quantify the antibacterial ability, the antibacterial ratio was calculated based on the following Equation (1).

Antibacterial ratio (\%)

$=\left(N_{\text {Blank }}-N_{\text {samples }}\right) / N_{\text {Blank }} \times 100 \%$,

where $N_{\text {Blank }}$ is the average number of bacteria in the blank group (CFU/sample) and $N_{\text {samples }}$ is the average number of bacteria in the evaluated sample (CFU/sample).

\section{Live/dead bacterial viability assay}

To visualize the viable bacterial cells on the $\mathrm{KNNCu}$ samples, a LIVE/DEAD Baclight bacterial viability kit (L7012) with two staining agents was used. The SYTO ${ }^{\circ} 9$ is a green-fluorescent nucleic acid stain that penetrates all bacteria. In contrast, the propidium iodide (PI), a rednucleic acid stain, only penetrates bacteria with damaged membranes. The ratio of red to green fluorescence emitted by bacteria stained with an appropriate mixture of these stains reflects the cellular permeability and viability. Thus, the dead, dying and living bacteria can be distinguished under the confocal laser scanning microscope (CLSM). After treatment with $\mathrm{KNNCu}(n=3)$, both $E$. coli and $S$. aureus were stained with the dye mixture (combine equal volumes of SYTO 9 and PI in a microfuge tube) for $15 \mathrm{~min}$ at room temperature in the dark. The stained bacterial cells were observed using a CLSM (Zeiss LSM 780, Germany).

\section{Bacterial morphology evaluation}

After treatment of the samples $(n=3)$ and bacteria, bacteria were fixed with $3 \%$ glutaraldehyde in $0.1 \mathrm{~mol} \mathrm{~L}^{-1}$ PBS ( $\mathrm{pH} \mathrm{7.4)}$ at $4^{\circ} \mathrm{C}$ for $4 \mathrm{~h}$ at room temperature. After being washed with PBS three times, bacteria were dehydrated with a graded ethanol series $(30 \%, 50 \%, 70 \%$, $80 \%, 90 \%, 95 \%$, and $100 \%, v / v$ ethanol, for $15 \mathrm{~min}$ each treatment). The ethanol was replaced with isoamyl acetate for 20 min twice. Finally, after drying with a $\mathrm{CO}_{2}$ critical point dryer (Autosamdri-815, Series A, Tousimis Research Corp, Rockville, MD, USA), the treated bacteria were observed by SEM (Zeiss EVO18, Carl Zeiss Company, Germany).

\section{Cellular ROS detection}

Intracellular reactive oxygen species (ROS) production was detected with an assay kit using the fluorescent probe dichorofluorescein diacetate (DCFH-DA). Bacteria treated with samples $(n=4)$ were stained with $10 \mu \mathrm{mol} \mathrm{L}^{-1}$ DCFH-DA for $30 \mathrm{~min}$ in the dark at room temperature. The intracellular ROS levels were recorded in the $500-700 \mathrm{~nm}$ emission range with an excitation wavelength of $488 \mathrm{~nm}$ and an emission wavelength of $525 \mathrm{~nm}$.

\section{Cytotoxicity assay}

Bone marrow mesenchymal stem cells (BMSCs) (CRL12424, ATCC, USA) were used to evaluate the cytotoxicity of $\mathrm{KNNCu}$ with a CCK-8 assay. A cell resuspension was seeded on the KNNCu sample surfaces $(n=4)$ in 48 well plates at a density of $1 \times 10^{4}$ cells $\mathrm{mL}^{-1}(500 \mu \mathrm{L}$ per well) for 1,3 and 5 days. CCK- 8 solution (Dojindo, Japan) was added to each well, and the samples were incubated at $37^{\circ} \mathrm{C}$ for $2 \mathrm{~h}$. The reacted solution was transferred to a new 96-well plate. The optical density (OD) was measured at a wavelength of $450 \mathrm{~nm}$ using a spectral scanning multimode reader (Thermo Scientific Varioskan Flash, USA).

\section{Cytocompatibility assessment}

The cytocompatibility of the $\mathrm{KNNCu}$ samples was assessed with the use of a live/dead staining assay. BMSCs were seeded on the $\mathrm{KNNCu}$ samples $(n=3)$ and then cultured. After rinsing with PBS three times, BMSCs were stained with the prepared dyeing fluid (Calcein AM and PI mixed at 2:5) for $15 \mathrm{~min}$ at $37^{\circ} \mathrm{C}$. Afterwards, the stained BMSCs were observed with an inverted fluorescence microscope (Nikon Eclipse Ti-U, Japan).

\section{Cell spreading behavior observation}

Cell spreading behavior was examined for the mouse BMSCs on the KNNCu samples. BMSCs and the samples $(n=3)$ cultured for $48 \mathrm{~h}$ were used for staining. These materials were washed with PBS three times. Then, cells were fixed with $4 \%$ paraformaldehyde for $10 \mathrm{~min}$, and 
washed with PBS containing $0.1 \%$ Triton X-100 for 5 min. Afterwards, cells were stained with an ActinTracker Green (Beyotime, Beijing, China) and DAPI (Beyotime Biotechnology, China). The cell cytoskeleton was observed by the CLSM. The average spreading area of cells was determined by analyzing their Actin-Tracker Green fluorescence images using the open-source software ImageJ.

\section{Copper ions of bacteria absorption test}

The $\mathrm{KNNCu}$ samples $(n=4)$ were cocultured for $2,4,8$ and $12 \mathrm{~h}$ with a bacterial suspension $\left(10^{6} \mathrm{CFU} / \mathrm{mL}\right)$, respectively. Then, the bacterial suspension was collected by centrifuging at $8000 \times \mathrm{g}$ for $10 \mathrm{~min}$. The supernatant was discarded, and $50 \mu \mathrm{L}$ of lysozyme was used to dissolve the bacteria at $37^{\circ} \mathrm{C}$ for $10 \mathrm{~min}$. Then, $5 \mathrm{~mL}$ of ultrapure water was added to dilute the dissolved solution. The filtered solution was used for testing by inductively coupled plasma mass spectrometry (ICP-MS) (Thermo, ICAP RQ) to evaluate the concentration of $\mathrm{Cu}^{2+}$ ions.

\section{Data analysis}

All data are presented as the means \pm standard deviation (S.D.). A two-tailed Student's $t$-test was used for twogroup comparisons and the statistical significance testing. * $p<0.05 ;{ }^{* *} p<0.01 ;{ }^{* * *} p<0.001$.

\section{RESULTS AND DISCUSSION}

\section{Preparation and characterization of $\mathrm{KNNCu}$}

The material model of ferroelectric $\mathrm{Cu}$-doped implant, $\mathrm{KNNCu}$, was constructed via a solid-state sintering process [21]. The SEM image of $\mathrm{KNNCu}$ displays a uniform microstructure (Fig. 1a). EDS mapping confirms that $\mathrm{Cu}$ element uniformly distributes on the $\mathrm{KNNCu}$ surface (Fig. 1b). To analyze the valence states of the doping copper element in $\mathrm{KNNCu}$, XPS analysis was carried out (Fig. S1a in Supplementary information). The $\mathrm{Cu} 2 \mathrm{p}$ spectrum shows satellite peaks at 931.9 and $952.0 \mathrm{eV}$ (Fig. S1b1), indicating that copper element is doped into the KNN. There is a slight shift towards high binding energy of $\mathrm{Nb}$ atoms at 205.97 and $208.58 \mathrm{eV}$ in $\mathrm{KNNCu}$ (Fig. S1b2). This can be attributed to B-site replacement of $\mathrm{Nb}^{5+}$ ions by $\mathrm{Cu}^{2+}$ ions, which is in accordance with the similar ionic radii between $\mathrm{Cu}^{2+}(0.73 \AA)$ and $\mathrm{Nb}^{5+}$ $(0.64 \AA)[22,23]$. XRD analysis was performed to examine the crystal phase of $\mathrm{KNNCu}$, which indicates that $\mathrm{KNNCu}$ possesses two peaks near $45^{\circ}$ with a perovskite structure $\left(\mathrm{ABO}_{3}\right)$ (Fig. 1c). The relative intensity of the $(002) /(200)$ peaks of the $\mathrm{KNNCu}$ is 1.5 , which indicates the coexistence of orthorhombic and tetragonal phases in the $\mathrm{KNNCu}$ sample, whose crystalline phase is a typical piezoelectric phase composition [24]. To examine the
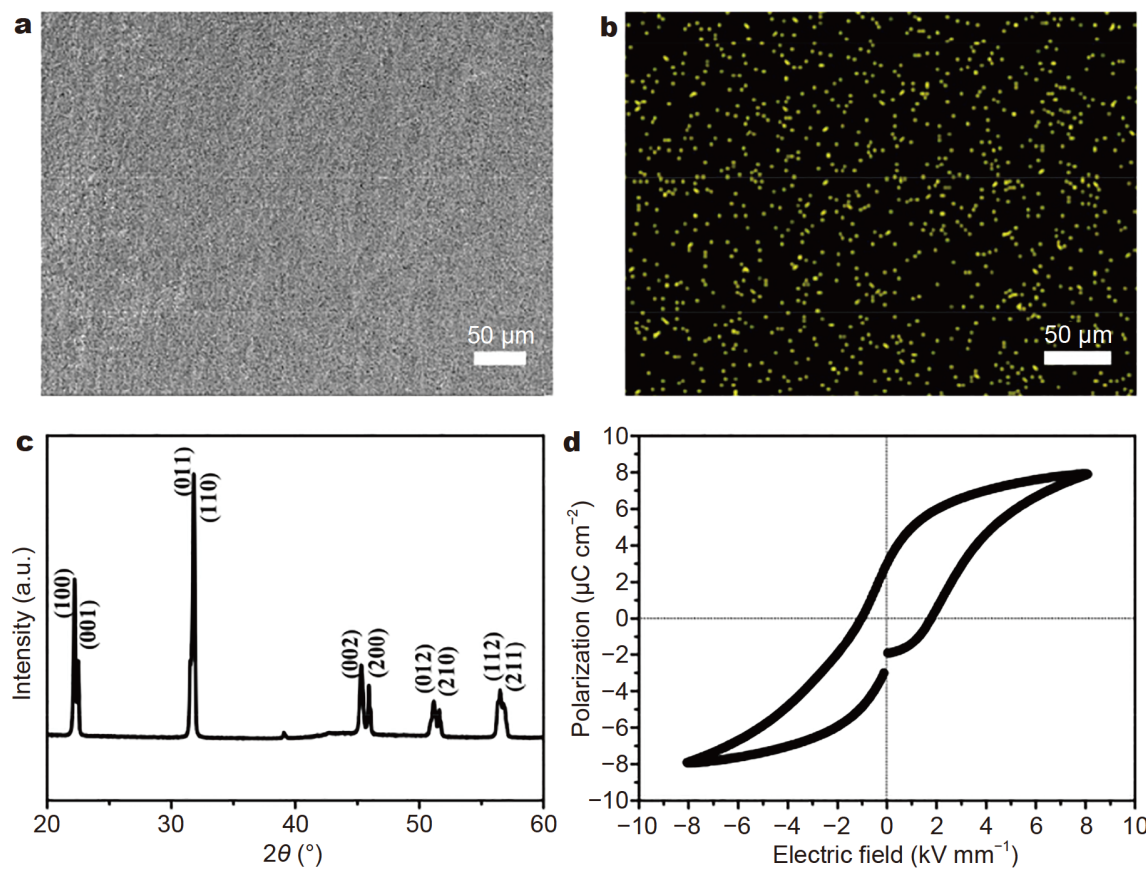

Figure 1 Characteriazation of KNNCu. (a) SEM image; (b) Cu elemental mapping of KNNCu surface; (c) XRD pattern; (d) $P$-E hysteresis loop. The results confirm the construction of $\mathrm{KNNCu}$ with ferroelectric properties. 
ferroelectric property of $\mathrm{KNNCu}$, the $P-E$ hysteresis loop of $\mathrm{KNNCu}$ was detected. The results show that $\mathrm{KNNCu}$ possesses a representative $P$ - $E$ hysteresis loop. The remnant polarization $\left(P_{\mathrm{r}}\right)$ of $\mathrm{KNNCu}$ is $6.50 \mu \mathrm{C} \mathrm{cm}{ }^{-2}$, which confirms that $\mathrm{KNNCu}$ possesses good ferroelectric property (Fig. 1d) [25-28].

To modulate the implant surface potential, and thus the $\mathrm{EEF}, \mathrm{KNNCu}$ was polarized using corona polarization. The SEM images indicate that $\mathrm{KNNCu}$ morphologies remain unchanged before and after polarization (Fig. S2). The SKPM results confirm that the KNNCu samples polarized under different external electric fields exhibit different surface potentials (Fig. 2). The SKPM results of $\mathrm{KNNCu}$ indicate that the surface potentials of $\mathrm{M}-\mathrm{KNNCu}$ (Fig. 2c) and $\mathrm{H}-\mathrm{KNNCu}$ (Fig. 2d) increase by approximately 54 and $110 \mathrm{mV}$ compared with $\mathrm{L}-\mathrm{KNNCu}$ (Fig. 2b), respectively. Meanwhile, as the bacterial cell membrane potential can be regarded as constant, the intensity of the EEF is proportional to the surface potential of $\mathrm{KNNCu}$.

\section{Antibacterial property under EEF}

After the EEF was constructed between the implant and the negatively-charged bacterial cell membrane, the an- tibacterial efficacy of $\mathrm{KNNCu}$ with the EEF-mediated $\mathrm{Cu}^{2+}$ ion transport was examined. The $\mathrm{KNNCu}$ samples and control were cocultured with E. coli and S. aureus for $12 \mathrm{~h}$, respectively [29]. The antibacterial ratio was first quantitatively examined by using a plate counting method (Fig. 3a). Compared with the other three groups $(\mathrm{KNN}, \mathrm{L}-\mathrm{KNNCu}$, and $\mathrm{M}-\mathrm{KNNCu})$, the $\mathrm{H}-\mathrm{KNNCu}$ group (the highest EEF intensity group) shows a remarkable antibacterial activity (100\% antibacterial ratio with both $E$. coli and S. aureus). The $\mathrm{M}-\mathrm{KNNCu}$ and L$\mathrm{KNNCu}$ with relatively low polarization electric potentials and lower EEF intensities suffer decreased antibacterial ratios (Fig. 3b). These results confirm the proposed mechanism that enhanced $\mathrm{Cu}^{2+}$ ion transport to target bacteria under EEF will promote the bacterial killing efficacy. Furthermore, the bacteria were stained with live/dead cell-staining kits, wherein green fluorescent $\mathrm{SYTO}^{\circ} 9$ enters live cells, and red fluorescent PI only enters cells with damaged cell membranes [30,31]. Schematic diagrams of the relative EEF intensity between the membrane and polarized $\mathrm{KNNCu}$ are shown in Fig. 4. The fluorescent images (Fig. 4) show that the $\mathrm{H}-\mathrm{KNNCu}$ group has the largest number of dead E. coli and S. aureus cells, followed by the $\mathrm{M}-\mathrm{KNNCu}$ group, while most

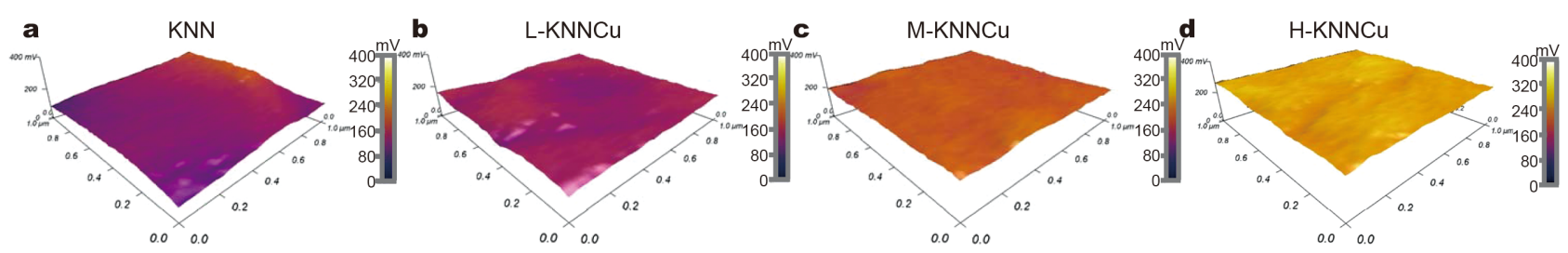

Figure 2 SKPM characterization of the KNNCu samples. (a) KNN (142.85 $\pm 23.89 \mathrm{mV})$; (b) L-KNNCu (149.51 $\pm 11.28 \mathrm{mV})$; (c) $\mathrm{M}-\mathrm{KNNCu}$ $(202.95 \pm 7.05 \mathrm{mV})$; (d) $\mathrm{H}-\mathrm{KNNCu}(261.81 \pm 7.20 \mathrm{mV})$. These results indicate that the surface potential of $\mathrm{KNNCu}$, and thus the EEF, can be modulated via external electric field polarization.
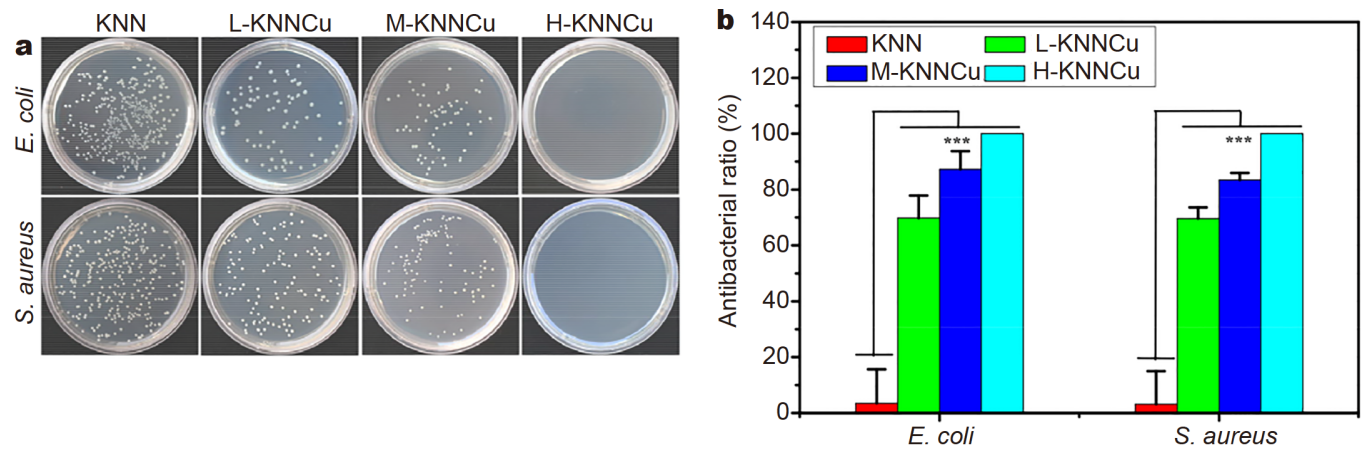

Figure 3 Evaluation of the antibacterial performances of the KNNCu samples under EEF. (a) Bacterial culture plate colony units incubated with $\mathrm{KNN}, \mathrm{L}-\mathrm{KNNCu}, \mathrm{M}-\mathrm{KNNCu}$, and $\mathrm{H}-\mathrm{KNNCu}$. (b) Antibacterial ratios of E. coli and S. aureus after incubation with $\mathrm{KNN}, \mathrm{L}-\mathrm{KNNCu}, \mathrm{M}-\mathrm{KNNCu}$, and $\mathrm{H}-\mathrm{KNNCu}$. These results indicate that the $\mathrm{H}-\mathrm{KNNCu}$ group with the highest EEF intensity achieves $100 \%$ antibacterial ratio. ${ }^{*} p<0.05 ;{ }^{* *} p<0.01$; ${ }^{* * *} p<0.001$. 


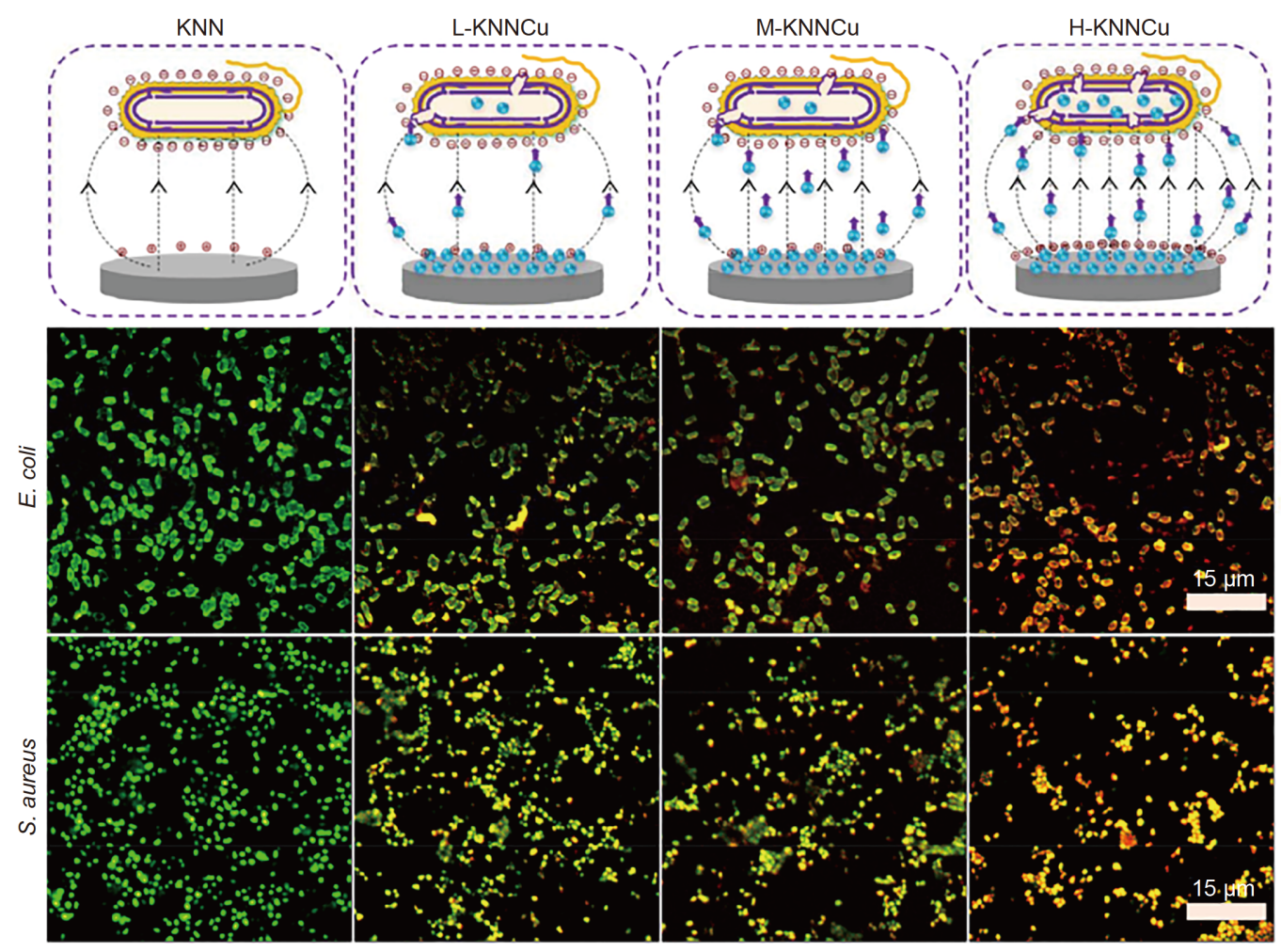

Figure 4 Schematic diagrams of the relative EEF intensity between bacteria membrane and polarized $\mathrm{KNNCu}$ and confocal flurescence microscopy images of the live/dead staining assay of $E$. coli and $S$. aureus incubated with $\mathrm{KNN}, \mathrm{L}-\mathrm{KNNCu}, \mathrm{M}-\mathrm{KNNCu}$, and $\mathrm{H}-\mathrm{KNNCu}$.

bacterial cells are still live for the other two groups, KNN and $\mathrm{L}-\mathrm{KNNCu}$. Thus, $\mathrm{H}-\mathrm{KNNCu}$ shows strong antibacterial abilities against E. coli and S. aureus. And the number of dead bacteria increases with the increase of EEF intensity. These results are consistent with the results of the CFU analysis.

\section{Antibacterial mechanism under EEF}

To verify the antibacterial mechanism of EEF-mediated antibacterial ion transport, the $\mathrm{KNNCu}$ samples were firstly cocultured with E. coli and S. aureus for 2, 4, 8 and $12 \mathrm{~h}$, and then the $\mathrm{Cu}^{2+}$ ions transport to target bacteria were extracted and measured via ICP-MS, respectively. Intriguingly, the amount of $\mathrm{Cu}^{2+}$ ions transport to target bacteria increases with increasing time and EEF intensity (Fig. 5a). The amount of $\mathrm{Cu}^{2+}$ ions from the $\mathrm{H}-\mathrm{KNNCu}$ group transport to target $E$. coli bacteria under EEF increases by only about $35 \%$ compared with that of L$\mathrm{KNNCu}$ group at the first $2 \mathrm{~h}$, respectively. With coculture time increasing to $12 \mathrm{~h}$, the amount of $\mathrm{Cu}^{2+}$ ions to target bacteria from $\mathrm{H}-\mathrm{KNNCu}$ group increases by $140 \%$ compared with that of L-KNNCu group. In short, the amount of $\mathrm{Cu}^{2+}$ ions targeting bacteria increases with the increase of EEF intensity and the increase of time, respectively. Meanwhile, the cumulative release profiles of $\mathrm{Cu}^{2+}$ ions from the $\mathrm{L}-\mathrm{KNNCu}$ and $\mathrm{H}-\mathrm{KNNCu}$ groups in a PBS solution were conducted via ICP-MS, which are shown in Fig. S3. Firstly, the release profiles indicate that $\mathrm{Cu}^{2+}$ ions continuously release from the $\mathrm{L}-\mathrm{KNNCu}$ and $\mathrm{H}-\mathrm{KNNCu}$ surfaces, with a similar release rate. To further explicate the role of EEF in bacterial killing, we compared the amounts of $\mathrm{Cu}^{2+}$ ions that release from L-KNNCu and $\mathrm{H}-\mathrm{KNNCu}$ and the amounts of $\mathrm{Cu}^{2+}$ ions that transport to target bacteria. As shown in Table S1, the results indicate that after $12 \mathrm{~h}$ culture, the amount of $\mathrm{Cu}^{2+}$ ions released from $\mathrm{H}-\mathrm{KNNCu}$ increased by about $14.90 \%$ compared with that from L-KNNCu. Nevertheless, after $12 \mathrm{~h}$ culture, we found that the amount of $\mathrm{Cu}^{2+}$ ions transport to target bacteria from $\mathrm{H}-\mathrm{KNNCu}$ was up to $140 \%$ more than that from L-KNNCu. The above results indicate that the increase of EEF intensity has a slight effect on the release of $\mathrm{Cu}^{2+}$ ions, but a more significant effect on the increase of the amount of ions target to bacteria, which demonstrates the significant role of EEF in promoting $\mathrm{Cu}^{2+}$ ions to transport to target bacteria. Actually, in a bacterial environment, antibacterial ion will 

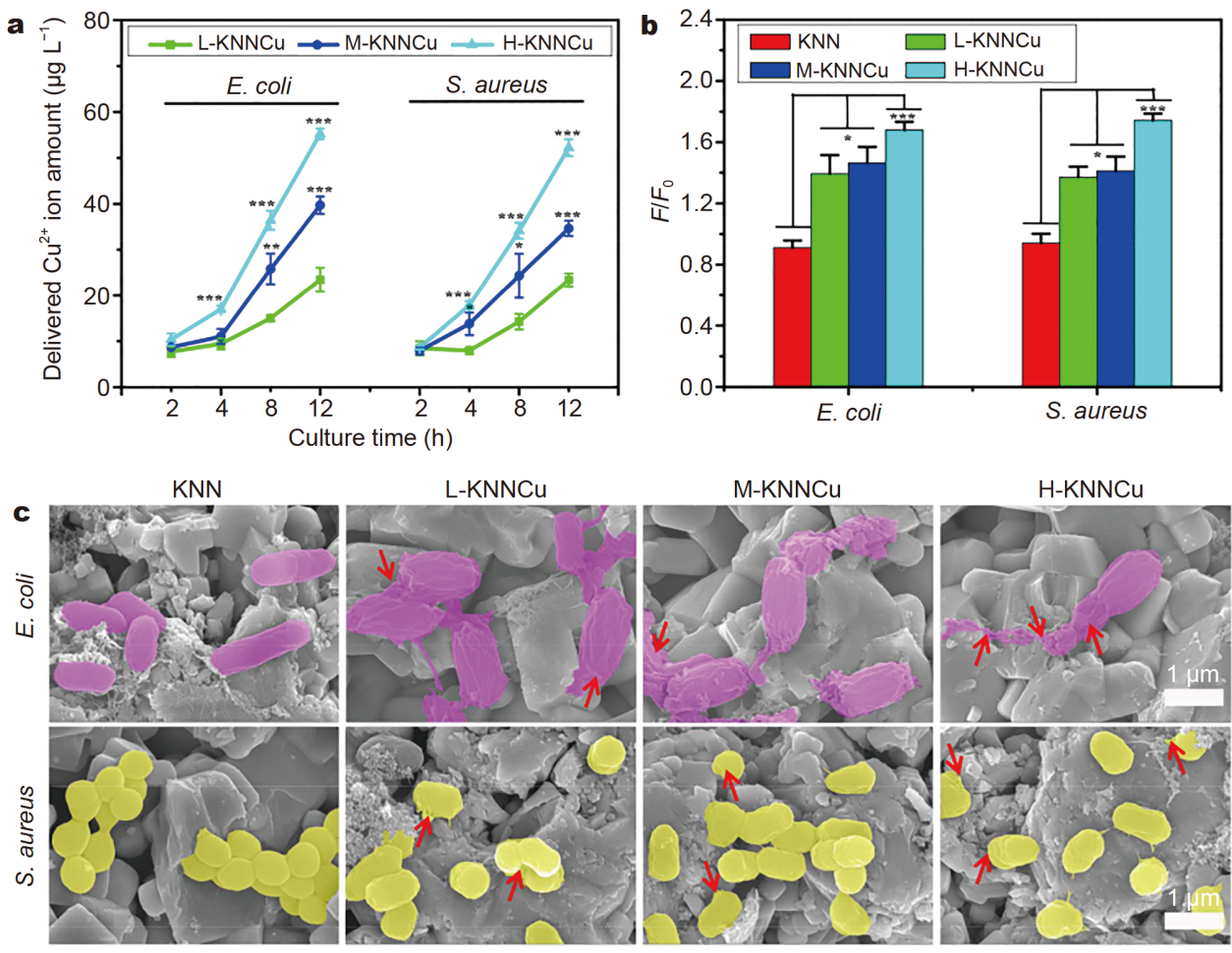

Figure 5 EEF-mediated $\mathrm{Cu}^{2+}$ ion transport and its effect on E. coli and S. aureus. (a) Amounts of $\mathrm{Cu}^{2+}$ ions transport to bacteria after coculture with $\mathrm{L}-\mathrm{KNNCu}, \mathrm{M}-\mathrm{KNNCu}$, and $\mathrm{H}-\mathrm{KNNCu}$ for 2, 4, 8 and $12 \mathrm{~h}$, respectively. (b) Quantification of ROS levels in E. coli and S. aureus after cocultured with $\mathrm{KNN}, \mathrm{L}-\mathrm{KNNCu}, \mathrm{M}-\mathrm{KNNCu}$, and $\mathrm{H}-\mathrm{KNNCu}$ for $12 \mathrm{~h}$ with the ROS assay kit. $F / F_{0}$ represents the ratio of the fluorescence intensities of the experimental group to that of the blank control. (c) SEM images of E. coli and S. aureus treated with KNN, L-KNNCu, M-KNNCu, and $\mathrm{H}-\mathrm{KNNCu}$ for $12 \mathrm{~h}$, respectively. E. coli and S. aureus are pseudo-colored. The arrows indicate bacteria with damaged cell membranes. These results confirm that EEF can mediate directional and quantitative transport of antibacterial ions to target bacteria. A two-tailed Student's $t$-test was used for the statistical significance testing. ${ }^{*} p<0.05 ;{ }^{* *} p<0.01 ; \stackrel{* * *}{p}<<0.001$.

exhibit diffusion, convection and electric migration. As the temperature and ion concentration gradient are relatively stable in the surrounding bacterial environment, the diffusion- and convection-driven transport of antibacterial ions can be ignored. Thus the enhanced $\mathrm{Cu}^{2+}$ ion transport from $\mathrm{KNNCu}$ to bacteria could be attributed to the electric migration under the EEF to transport $\mathrm{Cu}^{2+}$ ions along the tangential direction of the electric field line to reach the bacterial surfaces. The migration rate of antibacterial ions under an EEF is proportional to the potential gradient and ionic mobility of the electric field. The relationship among migration rate, potential gradient and ionic mobility can be expressed by Equation (2) [32]

$v=-z u F \nabla \Phi$,

where $v$ is the migration rate, $z$ is the number of electronic charges of the ion, $u$ is a proportionality factor that relates how fast the ion moves in response to an electric field, which is called ionic mobility; $F$ is the Faraday's constant; and $\Phi$ is the potential gradient of EEF in the solution, which can form electric field. Thus, under the guidance of EEF, directional and quantitative transport of antibacterial ions to target bacteria is achieved.

According to the above proof, different EEF intensities can mediate the amount of antibacterial ions transport to bacteria, which might enhance the bacteria-killing efficacy. As antibacterial ions mainly kill bacteria via intracellular ROS enrichment, we then detected the effect of EEF-mediated ion transport on ROS genenration. Intracellular ROS generation was measured using DCFH$\mathrm{DA}$ as a fluorescent staining probe after bacteria were incubated for $12 \mathrm{~h}$ with the $\mathrm{KNNCu}$ samples and control group [33]. The ROS production results (Fig. 5b) indicate that there is more ROS production in bacteria cocultured with $\mathrm{H}-\mathrm{KNNCu}$ because more $\mathrm{Cu}^{2+}$ ions are targeted to the bacterial cell membrane. This result may be due to the fact that the amount of $\mathrm{Cu}^{2+}$ ions transport to bacteria under the highest EEF intensity is relatively large, which leads to the abnormal ion exchange between the intracellular and extracellular surrounding, and thus causes 
abnormal respiration process to produce more ROS [3436]. To further investigate the antibacterial behavior at different EEF intensities, the morphologies of E. coli and $S$. aureus adhering to the $\mathrm{KNNCu}$ samples and control were observed by SEM (Fig. 5c). As shown in the SEM images, bacteria on $\mathrm{KNN}$ show a clear edge and appear smooth. For bacteria on $\mathrm{L}-\mathrm{KNNCu}, \mathrm{M}-\mathrm{KNNCu}$ and $\mathrm{H}-$ $\mathrm{KNNCu}$, some cell membranes are damaged, which shows a rough fold. In particular, seriously collapsed and split membranes are observed in the group treated with $\mathrm{H}-\mathrm{KNNCu}$. The bacteria gradually become irregular in shape and wizen due to extensive collapse of the cell membranes, followed by massive leakage of cell substances, such as proteins and DNA, similar to the previous reports [37-39]. These results suggest that the EEF transport of $\mathrm{Cu}^{2+}$ ions to target bacterial cell membrane would disrupt cell membranes, and induce intracellular
ROS generation to damage the bacterial cell membranes, resulting in the leakage of intracellular contents and eventually the death of bacteria.

\section{Biocompatibility of $\mathrm{KNNCu}$}

To examine the potential toxicity of the $\mathrm{KNNCu}$ samples, CCK-8 test was first performed with mouse BMSCs (Fig. 6a). Cell activity can be assessed by the optical density (OD) values. The higher the OD value, the higher the cell activity. The OD values for the $\mathrm{KNNCu}$ samples are slightly lower than that for pure KNN after 1 day of incubation. Encouragingly, after the 3rd and 5th days of incubation, no statistic difference can be observed between the viabilities of BMSCs on $\mathrm{KNN}$ and the $\mathrm{KNNCu}$ samples. Live/dead cell staining was also conducted to examine the influence of the $\mathrm{KNNCu}$ samples on the BMSC viability (Fig. 6b). Hardly any dead cells on the
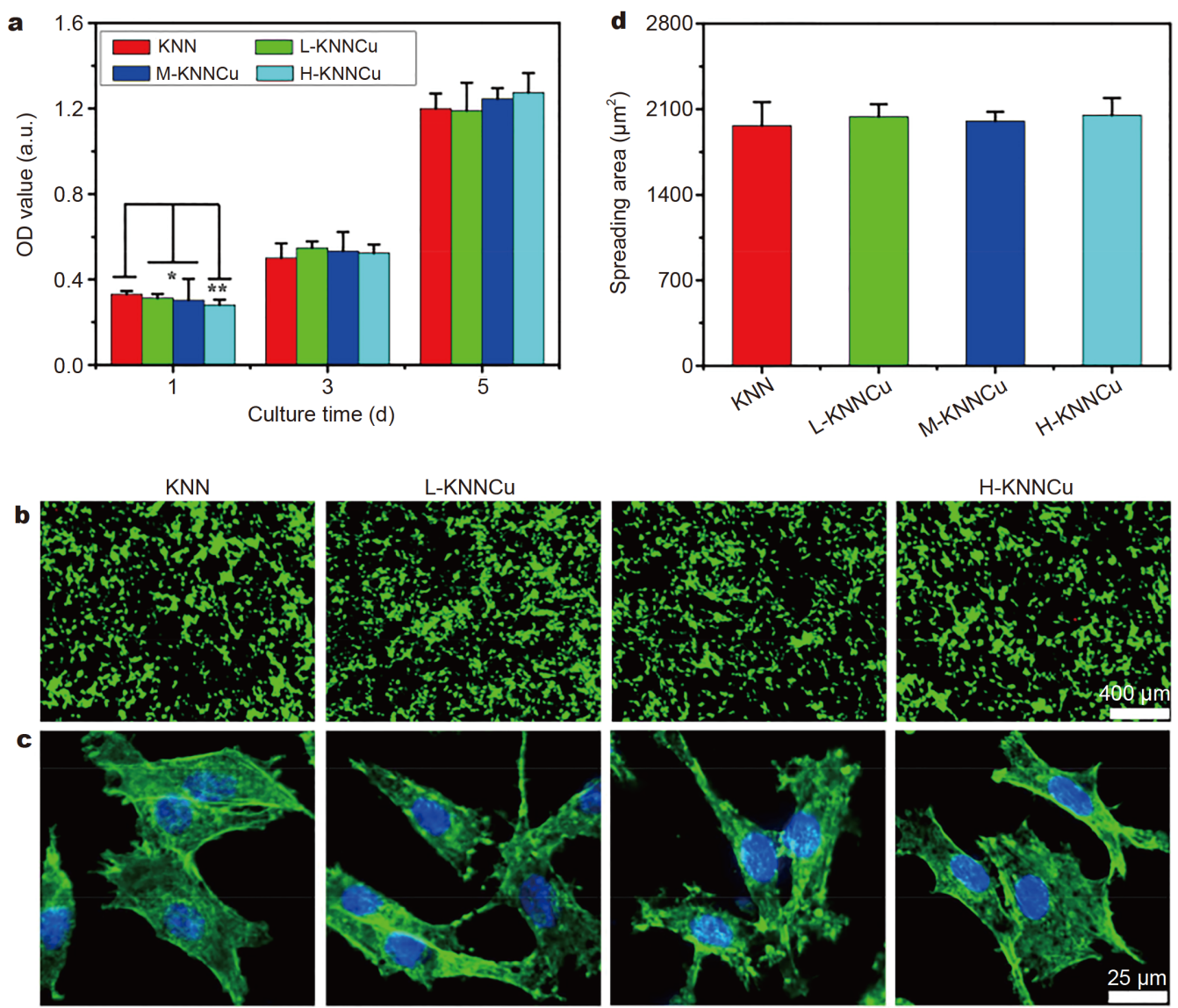

Figure 6 Biocompatibility assessment of the KNNCu samples. (a) Cytotoxicity of BMSCs incubated on KNN, L-KNNCu, M-KNNCu, and H-KNNCu for 1,3 , and 5 days assessed using a CCK-8 assay, respectively. (b) Live/dead cell stain of BMSCs incubated on KNN, L-KNNCu, M-KNNCu, and H$\mathrm{KNNCu}$ for $48 \mathrm{~h}$, respectively. The green fluorescence representes live cells and the red fluorescence representes dead cells. (c) Cytoskeletal stain of BMSCs incubated on KNN, L-KNNCu, M-KNNCu, and $\mathrm{H}-\mathrm{KNNCu}$ for $48 \mathrm{~h}$, respectively. (d) Average spreading areas of cytoskeleton in (c). ${ }^{*} p<0.05$; ${ }^{* *} p<0.01 ;{ }^{* * *} p<0.001$. 
$\mathrm{KNNCu}$ samples demonstrate excellent biocompatibility of these materials [40-42]. The good biocompatibility of $\mathrm{KNNCu}$ groups on BMSCs can be attributed to the relatively low-dose copper element incorporated into the $\mathrm{KNNCu}$ samples and appropriate surface electric properties after polarization. The relatively low-dose copper element incorporation ensures a relative low ion release level to maintain the bioactivity of $\mathrm{KNN}$, which is in accordance with previous research that the low-dose $\mathrm{Cu}^{2+}$ ions are biocompatible to cells $[43,44]$. And various previous studies also demonstrate the biocompatibility of polarized piezoelectric biomaterials, such as biocompatible ferroelectric NKN nanofibers [45], ferroelectric $\mathrm{LiNbO}_{3}[46,47]$ and barium titanate biomaterial $[48,49]$. Moreover, the cytoskeleton staining images show that the BMSCs are spreading out on the surfaces of KNN and the KNNCu samples (Fig. 6c). The statistical data (Fig. 6d) indicate there is no significant difference in the spreading areas among $\mathrm{KNN}$ and the $\mathrm{KNNCu}$ samples, which indicates that the $\mathrm{KNNCu}$ samples are favorable for cell spreading. Therefore, the polarized ferroelectric implant with the antibacterial ion transport system to target baceria can not only enhance the antibacterial property, but also have good biocompatibility.

\section{CONCLUSIONS}

In summary, this work provides a ferroelectric copperdoped implant model to construct EEF with bacterial cell membrane with the polarization parameters conveniently as a bridge for studying the effect of EEF on transport ratio of antibacterial ions to target bacteria. Interestingly, in an infectious bacterial environment, directional and quantitative transport of antibacterial ions to bacteria can be achieved via modulation of EEF. The high EEFmediated ion transport can achieve a $100 \%$ antibacterial ratio. This research demonstrates that EEF as a bridge heavily impacts the antibacterial performance, and concludes the significance of manipulating the implant surface charging property to control EEF-mediated antibacterial ions to target bacteria when designing antibacterial biomaterials.

\section{Received 4 February 2020; accepted 2 April 2020; published online 8 June 2020}

1 Jones KE, Patel NG, Levy MA, et al. Global trends in emerging infectious diseases. Nature, 2008, 451: 990-993

2 Qi GB, Zhang D, Liu FH, et al. An "on-site transformation" strategy for treatment of bacterial infection. Adv Mater, 2017, 29: 1703461

3 Lee JS, Murphy WL. Functionalizing calcium phosphate biomaterials with antibacterial silver particles. Adv Mater, 2013, 25:
1173-1179

4 Jin $\mathrm{X}$, Xiong $\mathrm{Y}-\mathrm{H}$, Zhang $\mathrm{X}-\mathrm{Y}$, et al. Self-adaptive antibacterial porous implants with sustainable responses for infected bone defect therapy. Adv Funct Mater, 2019, 29: 1807915

5 Wu Y, Song Z, Wang H, et al. Endogenous stimulus-powered antibiotic release from nanoreactors for a combination therapy of bacterial infections. Nat Commun, 2019, 10: 4464

6 Mouriño V, Cattalini JP, Boccaccini AR. Metallic ions as therapeutic agents in tissue engineering scaffolds: An overview of their biological applications and strategies for new developments. J R Soc Interface, 2012, 9: 401-419

7 Li X, Bai H, Yang Y, et al. Supramolecular antibacterial materials for combatting antibiotic resistance. Adv Mater, 2018, 31: 1805092

8 Hwang IY, Koh E, Kim HR, et al. Reprogrammable microbial cellbased therapeutics against antibiotic-resistant bacteria. Drug Resistance Updates, 2016, 27: 59-71

9 Arciola CR, Campoccia D, Montanaro L. Implant infections: Adhesion, biofilm formation and immune evasion. Nat Rev Microbiol, 2018, 16: 397-409

10 Javid A, Kumar M, Yoon S, et al. Size-controlled growth and antibacterial mechanism for $\mathrm{Cu}: \mathrm{C}$ nanocomposite thin films. Phys Chem Chem Phys, 2016, 19: 237-244

11 Wright ME, Parrag IC, Yang M, et al. Electrospun polyurethane nanofiber scaffolds with ciprofloxacin oligomer versus free ciprofloxacin: Effect on drug release and cell attachment. J Control Release, 2017, 250: 107-115

12 Amin Yavari S, Loozen L, Paganelli FL, et al. Antibacterial behavior of additively manufactured porous titanium with nanotubular surfaces releasing silver ions. ACS Appl Mater Interfaces, 2016, 8: 17080-17089

13 Hussain S, Joo J, Kang J, et al. Antibiotic-loaded nanoparticles targeted to the site of infection enhance antibacterial efficacy. Nat Biomed Eng, 2018, 2: 95-103

14 Zhang $\mathrm{P}$, Zheng J, Wang Z, et al. An in situ potential-enhanced ion transport system based on FeHCF-PPy/PSS membrane for the removal of $\mathrm{Ca}^{2+}$ and $\mathrm{Mg}^{2+}$ from dilute aqueous solution. Ind Eng Chem Res, 2016, 55: 6194-6203

15 Wang W, Zhu L, Lv P, et al. Novel candy-like $\mathrm{Cu}_{4} \mathrm{O}_{3}$ microstructure: Facile wet chemical synthesis, formation mechanism, and good long-term antibacterial activities. ACS Appl Mater Interfaces, 2018, 10: 37287-37297

16 Zhang L, Jiao L, Zhong J, et al. Lighting up the interactions between bacteria and surfactants with aggregation-induced emission characteristics. Mater Chem Front, 2017, 1: 1829-1835

17 Du X, Zhang D, Ma X, et al. Electrochemical redox induced rapid uptake/release of $\mathrm{Pb}(\mathrm{II})$ ions with high selectivity using a novel porous electroactive HZSM-5@PANI/PSS composite film. Electrochim Acta, 2018, 282: 384-394

18 Gao F, Du X, Hao X, et al. Electrical double layer ion transport with cell voltage-pulse potential coupling circuit for separating dilute lead ions from wastewater. J Membrane Sci, 2017, 535: 2027

19 Chai Z, Hu X, Lu W. Cell membrane-coated nanoparticles for tumor-targeted drug delivery. Sci China Mater, 2017, 60: 504-510

20 Yu P, Ning C, Zhang Y, et al. Bone-inspired spatially specific piezoelectricity induces bone regeneration. Theranostics, 2017, 7: 3387-3397

21 Wu J, Xiao D, Zhu J. Potassium-sodium niobate lead-free piezoelectric materials: Past, present, and future of phase boundaries. Chem Rev, 2015, 115: 2559-2595 
22 Yang SL, Tsai CC, Liou YC, et al. Differences between copperoxide- and zinc-oxide-doped sodium potassium niobate ceramics. J Am Ceram Soc, 2012, 95: 2110-2112

23 Wan J, Chen W, Jia C, et al. Defect effects on $\mathrm{TiO}_{2}$ nanosheets: Stabilizing single atomic site $\mathrm{Au}$ and promoting catalytic properties. Adv Mater, 2018, 30: 1705369

24 Yang SL, Tsai CC, Liou YC, et al. Investigation of CuO-doped NKN ceramics with high mechanical quality factor synthesized by a B-site oxide precursor method. J Am Ceram Soc, 2012, 95: 10111017

25 Yang SL, Hong CS, Tsai CC, et al. Effects of modified-process on the microstructure, internal bias field, and activation energy in CuO-doped NKN ceramics. J Eur Ceramic Soc, 2012, 32: 16431650

26 Shao B, Qiu JH, Zhu KJ, et al. Effect of $\mathrm{CuO}$ on dielectric and piezoelectric properties of $\left(\mathrm{K}_{0.4425} \mathrm{Na}_{0.52} \mathrm{Li}_{0.0375}\right)\left(\mathrm{Nb}_{0.87} \mathrm{Ta}_{0.06} \mathrm{Sb}_{0.07}\right) \mathrm{O}_{3}$ ceramics. J Alloys Compd, 2012, 515: 128-133

27 Marandian Hagh N, Kerman K, Jadidian B, et al. Dielectric and piezoelectric properties of $\mathrm{Cu}^{2+}$-doped alkali niobates. J Eur Ceramic Soc, 2009, 29: 2325-2332

28 Zhou JJ, Cheng LQ, Wang K, et al. The phase structure and electric properties of low-temperature sintered $(\mathrm{K}, \mathrm{Na}) \mathrm{NbO}_{3}$-based piezoceramics modified by CuO. Ceramics Int, 2014, 40: 2927-2931

29 Nasajpour A, Ansari S, Rinoldi C, et al. A multifunctional polymeric periodontal membrane with osteogenic and antibacterial characteristics. Adv Funct Mater, 2018, 28: 1703437

30 Schnaider L, Brahmachari S, Schmidt NW, et al. Self-assembling dipeptide antibacterial nanostructures with membrane disrupting activity. Nat Commun, 2017, 8: 1365

31 Xing J, Qi S, Wang Z, et al. Antimicrobial peptide functionalized conductive nanowire array electrode as a promising candidate for bacterial environment application. Adv Funct Mater, 2019, 29: 1806353

32 Paul D. Focussed electric field induced ion transport: A novel nano-patterning process. Dissertation for Master Degree. Ames: Lowa State University, 2010

33 Zhang Y, Wang L, Xu X, et al. Combined systems of different antibiotics with nano-CuO against Escherichia coli and the mechanisms involved. Nanomedicine, 2018, 13: 339-351

34 Liu C, Kong D, Hsu PC, et al. Rapid water disinfection using vertically aligned $\mathrm{MoS}_{2}$ nanofilms and visible light. Nat Nanotech, 2016, 11: 1098-1104

35 Wang C, Yue L, Wang S, et al. Role of electric field and reactive oxygen species in enhancing antibacterial activity: A case study of 3D $\mathrm{Cu}$ foam electrode with branched $\mathrm{CuO}-\mathrm{ZnO}$ NWs. J Phys Chem C, 2018, 122: 26454-26463

36 Zhang M, Zhang C, Zhai X, et al. Antibacterial mechanism and activity of cerium oxide nanoparticles. Sci China Mater, 2019, 62: 1727-1739

37 Zhao Y, Guo Q, Dai X, et al. A biomimetic non-antibiotic approach to eradicate drug-resistant infections. Adv Mater, 2019, 31: 1806024

38 Tan L, Li J, Liu X, et al. Rapid biofilm eradication on bone implants using red phosphorus and near-infrared light. Adv Mater, 2018, 30: 1801808

39 Zhang D, Qian Y, Zhang S, et al. Alpha-beta chimeric polypeptide molecular brushes display potent activity against superbugs-me- thicillin resistant staphylococcus aureus. Sci China Mater, 2018, 62: 604-610

40 Zhang $\mathrm{X}$, Zhang $\mathrm{C}$, Lin $\mathrm{Y}$, et al. Nanocomposite membranes enhance bone regeneration through restoring physiological electric microenvironment. ACS Nano, 2016, 10: 7279-7286

41 Xiao J, Zhu Y, Huddleston S, et al. Copper metal-organic framework nanoparticles stabilized with folic acid improve wound healing in diabetes. ACS Nano, 2018, 12: 1023-1032

42 Romero-Sánchez LB, Marí-Beffa M, Carrillo $\mathrm{P}$, et al. Coppercontaining mesoporous bioactive glass promotes angiogenesis in an in vivo zebrafish model. Acta Biomater, 2018, 68: 272-285

43 Ning C, Wang X, Li L, et al. Concentration ranges of antibacterial cations for showing the highest antibacterial efficacy but the least cytotoxicity against mammalian cells: Implications for a new antibacterial mechanism. Chem Res Toxicol, 2015, 28: 1815-1822

44 Li M, Ma Z, Zhu Y, et al. Toward a molecular understanding of the antibacterial mechanism of copper-bearing titanium alloys against Staphylococcus aureus. Adv Healthcare Mater, 2016, 5: 557-566

45 Jalalian A, Grishin AM. Biocompatible ferroelectric ( $\mathrm{Na}, \mathrm{K}) \mathrm{NbO}_{3}$ nanofibers. Appl Phys Lett, 2012, 100: 012904

46 Vaněk $\mathrm{P}$, Kolská Z, Luxbacher $\mathrm{T}$, et al. Electrical activity of ferroelectric biomaterials and its effects on the adhesion, growth and enzymatic activity of human osteoblast-like cells. J Phys D-Appl Phys, 2016, 49: 175403

47 Carville NC, Collins L, Manzo M, et al. Biocompatibility of ferroelectric lithium niobate and the influence of polarization charge on osteoblast proliferation and function. J Biomed Mater Res, 2015, 103: 2540-2548

48 Park JB, Kelly BJ, Kenner GH, et al. Piezoelectric ceramic implants: in vivo results. J Biomed Mater Res, 1981, 15: 103-110

49 Ciofani G, Ricotti L, Canale C, et al. Effects of barium titanate nanoparticles on proliferation and differentiation of rat mesenchymal stem cells. Colloids Surfs B-Biointerfaces, 2013, 102: 312320

Acknowledgements This work was supported by the National Key R\&D Program of China (2018YFC1105304 and 2018YFC1105301), the National Natural Science Foundation of China (51772106, 31771080, 51702104, 51672088 and 31700880), the Natural Science Foundation of Guangdong Province (2016A030308014), the Joint Funds of the National Natural Science Foundation of China (U1501245), and the Science and Technology Innovation Team Project of Foshan (2015IT100062). We thank the Department of Information, General Hospital of Southern War Zone of Chinese People's Liberation Army for the E. coli and S. aureus clinical isolates.

Author contributions Zhai J, Zhou Y, Yu P and Ning C conceived the study. Zhai J was involved in all aspects of the study. Zhai J, Fan L and Luo $\mathrm{Y}$ contributed to the scheme. Wang Z performed the SKPM measurements. Wang X contributed to the ROS analysis. Xiao C, Li Y, Zhou Z, Li C, Qi S, Tan $G$ and Zhou L contributed to the improvement of the manuscript. Zhai J wrote the paper with significant contribution from Yu P.

Conflict of interest The authors declare no competing interest.

Supplementary information Supporting data are available in the online version of the paper. 


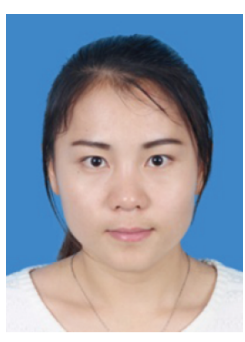

Jinxia Zhai is a doctoral student at South China University of Technology. Her current research mainly focuses on the design of ferroelectric implant materials and their applications in the field of biomedicine.

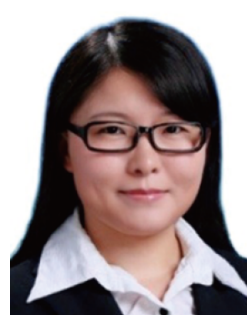

Yahong Zhou received her bachelor degree from Jilin University in 2009, and $\mathrm{PhD}$ degree from the Institute of Chemistry, Chinese Academy of Sciences in 2014. Afterwards, she was appointed as an assistant professor in Lei Jiang's group at the Technical Institute of Physics and Chemistry, Chinese Academy of Sciences. Her research interest includes bio-inspired interface with microfluidics, nanofluidics, smart bio-inspired porous membranes, and integrated as-prepared nanoporous membrane into energy devices.

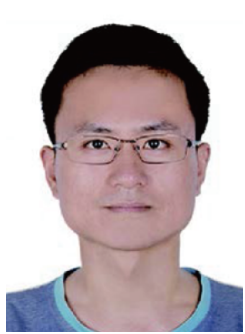

Peng Yu received his $\mathrm{PhD}$ degree in biomedical engineering from South China University of Technology in 2016. Now he is a researcher at the School of Materials Science and Engineering, South China University of Technology. His research interests focus on multiscale bone regenerative biomaterials, piezoelectric biomaterials and semi-conductive biomaterials.

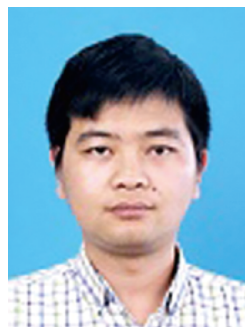

Lei Zhou received his $\mathrm{PhD}$ degree in biomedical engineering from South China University of Technology in 2018. Now he is a postdoctoral researcher at the School of Materials Science and Engineering, South China University of Technology. His research interests focus on multifunctional hydrogel biomaterials.

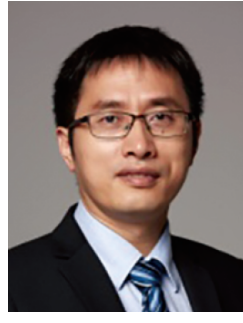

Chengyun Ning is currently a full professor in the School of Materials Science and Engineering, South China University of Technology. He is the director of Biomedical Engineering Key Laboratory of Guangdong Province, China, the Principle Investigator of the National Basic Research Program (973). His major research interests include surface modifications of implants and electroactive biomaterials.

\section{内源性电场调控抗菌离子传输以提高植入材料抗 菌性能}

翟锦霞 ${ }^{1,2 \dagger}$, 周亚红 ${ }^{3 \dagger}$, 王珍高 ${ }^{1,2}$, 范否 ${ }^{1,2}$, 肖才榕 ${ }^{1,2}$, 王晓岗 ${ }^{1,2}$, 李扬帆 ${ }^{1,2}$, 周正难 ${ }^{1,2}$, 罗义安 ${ }^{4}$, 黎昌昊 ${ }^{1,2}$, 戚穗坚 ${ }^{5}$, 谭帼馨 ${ }^{4}$, 周蕾 ${ }^{1,2^{*}}$, 于鹏 ${ }^{1,2^{*}}$, 宁成云 ${ }^{1,2}$

摘要 组织植入材料相关感染是临床治疗的一大顽疾, 基于抗菌离 子释放系统的抗菌植入材料是经济高效的抗生素治疗替代手段. 但过量释放的抗菌离子在杀灭细菌的同时也可能引起生物毒性. 因此, 如何提高释放离子的抗菌效率是急需解决的根本问题. 本研 究设计了一种负载低剂量抗菌离子的铁电植入材料, 该植入材料 表面电势可在不改变自身成份的前提下通过外源电场极化进行调 控. 研究发现上述铁电植入材料释放的抗菌离子将在植入材料自 身与带电细菌之间形成的内源性电场作用下定向输运到达细菌. 研究结果表明在 $12 \mathrm{~h}$ 内, 高表面电势植入材料向细菌输运的离子量 达到低表面电势植入材料输运量的 2.4 倍，从而使抗菌效率从 $65 \%$ 提高到 $100 \%$, 并展现出较低的细胞毒性. 本研究表明植入材料与生 命体间的内源性电场在介导物质传输中发挥重要作用, 为设计高 性能抗菌生物材料提供了一个新的视角. 